\title{
openheart Long-term survival in patients with isolated pulmonary valve stenosis: a not so benign disease?
}

\author{
Kristofer Skoglund (D , , ${ }^{1,2}$ Annika Rosengren, ${ }^{2}$ Georgios Lappas, ${ }^{1}$ \\ Maria Fedchenko, ${ }^{1,2}$ Zacharias Mandalenakis ${ }^{1,2}$
}

To cite: Skoglund $K$, Rosengren A, Lappas G, et al. Long-term survival in patients with isolated pulmonary valve stenosis: a not so benign disease?. Open Heart 2021;8:e001836. doi:10.1136/ openhrt-2021-001836

Received 26 August 2021 Accepted 31 August 2021

Check for updates

\section{C) Author(s) (or their} employer(s)) 2022. Re-use permitted under CC BY. Published by BMJ.

${ }^{1}$ Department of Molecular and Clinical Medicine, University of Gothenburg, Goteborg, Sweden ${ }^{2}$ Department of Cardiology, Sahlgrenska University Hospital, Goteborg, Sweden

\section{Correspondence to}

Dr Kristofer Skoglund; kristofer. skoglund@gu.se

\section{ABSTRACT}

Background and objectives During the last decades, the survival rates in patients with congenital heart disease have increased dramatically, particularly in patients with complex heart malformations. However, the survival in patients with simple defects is still unknown. We aimed to determine the characteristics and the risk of mortality in patients with isolated pulmonary valve stenosis (PS). Methods Swedish inpatient, outpatient and cause of death registries were used to identify patients born between 1970 and 2017 with a diagnosis of PS, without any other concomitant congenital heart lesion. For each patient with PS, 10 control individuals without congenital heart disease were matched by birth year and sex from the total population registry. We used median-unbiased method and Kaplan-Meier survival analysis to examine the risk of mortality.

Results We included 3910 patients with PS and 38770 matched controls. The median age of diagnosis of PS was 0.7 years (IQR 0.3-7.0). During a median follow-up of 13.5 years (IQR 6.5-23.5), 88 patients with PS and 192 controls died; 500 patients with PS (12\%) underwent at least one transcatheter or surgical valve intervention. The overall mortality rate was significantly higher in patients with PS compared with matched controls (HR 4.67, 95\% Cl 3.61 to $5.99, p=0.001)$. Patients with an early diagnosis of PS (0-1 year) had the highest risk of mortality (HR 10.99, $95 \%$ Cl 7.84 to 15.45 ).

Conclusions In this nationwide, register-based cohort study, we found that the risk of mortality in patients with PS is almost five times higher compared with matched controls. Patients with an early diagnosis of PS appears to be the most vulnerable group and the regular followup in tertiary congenital heart units may be the key to prevention.

\section{INTRODUCTION}

Evolution of care for patients with congenital heart disease has led to more than $97 \%$ of patients currently reaching adulthood. ${ }^{1-3}$ Isolated pulmonary valve stenosis (PS) is a relatively common malformation occurring in $8 \%-10 \%$ of all live births with congenital heart disease corresponding to one in every thousand babies born. ${ }^{4}$ Treatment for PS was originally limited to surgical valvulotomy,

\section{Key questions}

What is already known about this subject?

- During the last decades survival in patients with congenital heart disease has increased dramatically particularly in complex heart malformations Isolated pulmonary valve stenosis (PS) has in mild forms been considered associated with normal survival.

What does this study add?

- We found that the mortality risk for patients with PS was five times higher than in matched controls for both operated an unoperated patients. The highest risk was observed in patients with a diagnosis of PS in the first year of life appearing at an HR of 10.99.

How might this impact on clinical practice?

- In this national cohort study, we found that patients with PS had markedly higher mortality risk than matched controls and diagnosis of PS can not be considered a benign disease. Patients with diagnosis of PS in early life appears as a high-risk group and should be paid close attention in long-term follow-up.

but in recent decades, percutaneous balloon valvuloplasty has become the preferred treatment. $^{67}$ Long-term, event-free survival after valve intervention is $>90 \%$, but complications after interventions for PS include pulmonary valve regurgitation with possible right ventricular volume overload, occurs in one-third of patients. ${ }^{8-11}$ Furthermore right ventricular hypertrophy and stiffness related to right ventricular alterations can cause impaired function. ${ }^{12}$ In clinical study cohorts, untreated mild PS has been considered to be a benign disease and may associated with normal survival as well as a low risk for progression of this valvular disease ${ }^{13-17}$ Population-based studies with long-term follow-up in patients with PS with and without cardiac intervention are, however, limited and we are aware of no study that have 


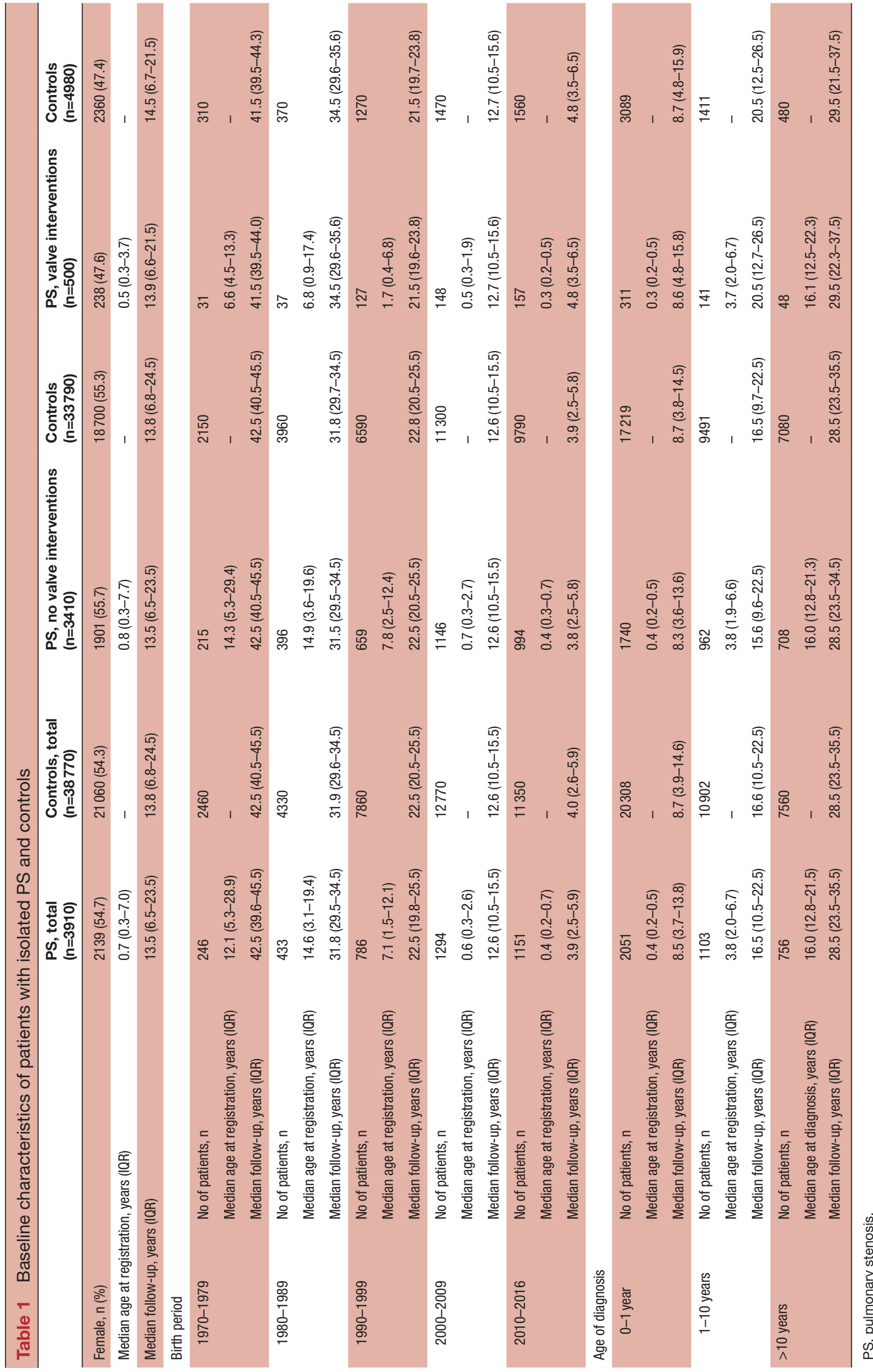




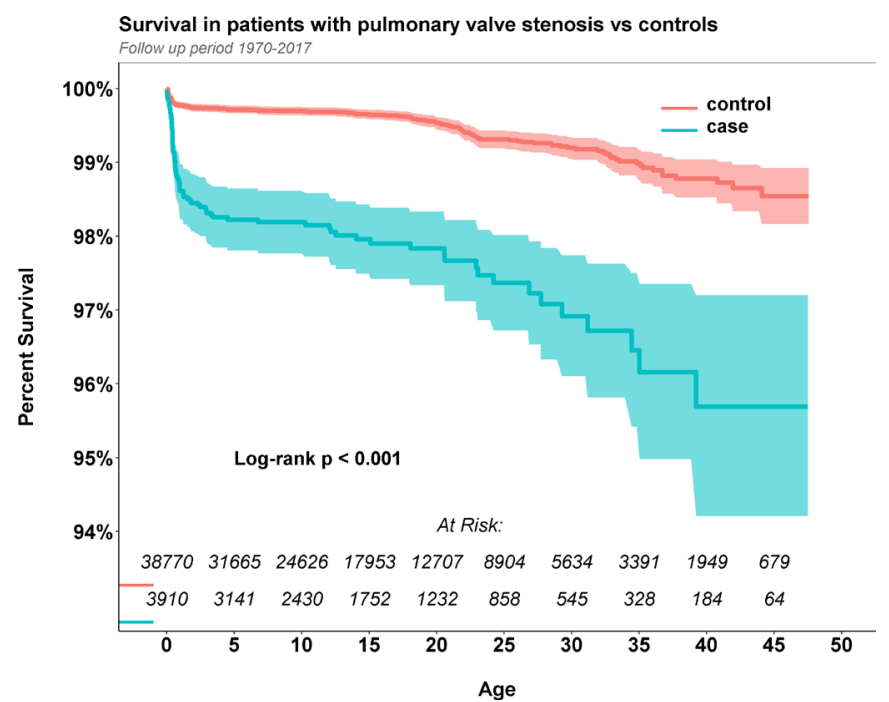

Figure 1 Kaplan-Meier estimated survival in patients with isolated pulmonary stenosis and matched controls.

followed unselected patients with PS in an entire nation from birth.

Therefore, this study aimed to determine the characteristics and the risk of mortality in patients with PS on a national level using Swedish medical registries.

\section{METHODS}

\section{Population}

The National Cause of Death Registry (complete since 1968), the National Hospital Inpatient Registry (initiated in 1964, complete since 1987, but with coverage of thoracic surgery since 1970) and the National Hospital Outpatient Registry (complete since 2001) were used to identify all patients born from 1970 to 2017 who had a registered diagnosis of PS at death, or at any visit to a Swedish hospital during a follow-up. Identification of patients with PS including subvalvular PS was by diagnosis codes according to the International Classification of Diseases, Revision 8 and Related Health Problems (ICD-8 and ICD-9: 7466, 7460, 424D, I370, I372 ; ICD-10: Q221, Q223 and Q243). Patients with any concomitant congenital heart lesions were excluded from the analysis, except for PS patients with also a pulmonary valve regurgitation diagnosis (ICD-8 and ICD-9: I371; ICD-10: Q22.2). For each patient with isolated PS, 10 control individuals without congenital heart disease were randomly matched by birth year and sex from the total population register.

Surgical or percutaneous valve interventions related to PS were defined as the presence of any code involving intervention to the right ventricular outflow tract and/ or pulmonary valve according to classification of surgical Procedures. $^{18}$

All personal identifiers were removed from the final dataset and replaced by a code.

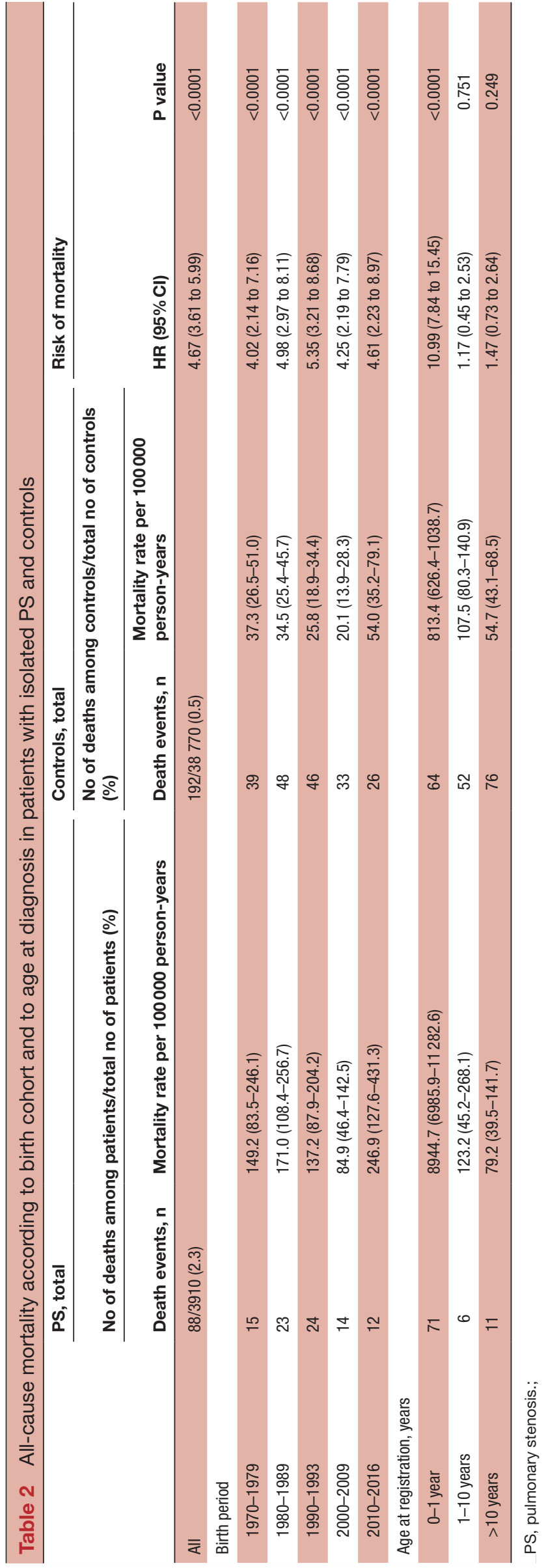


Table 3 All-cause mortality in patients with isolated PS (with and without valve interventions) and controls, according to birth cohort, to age at diagnosis

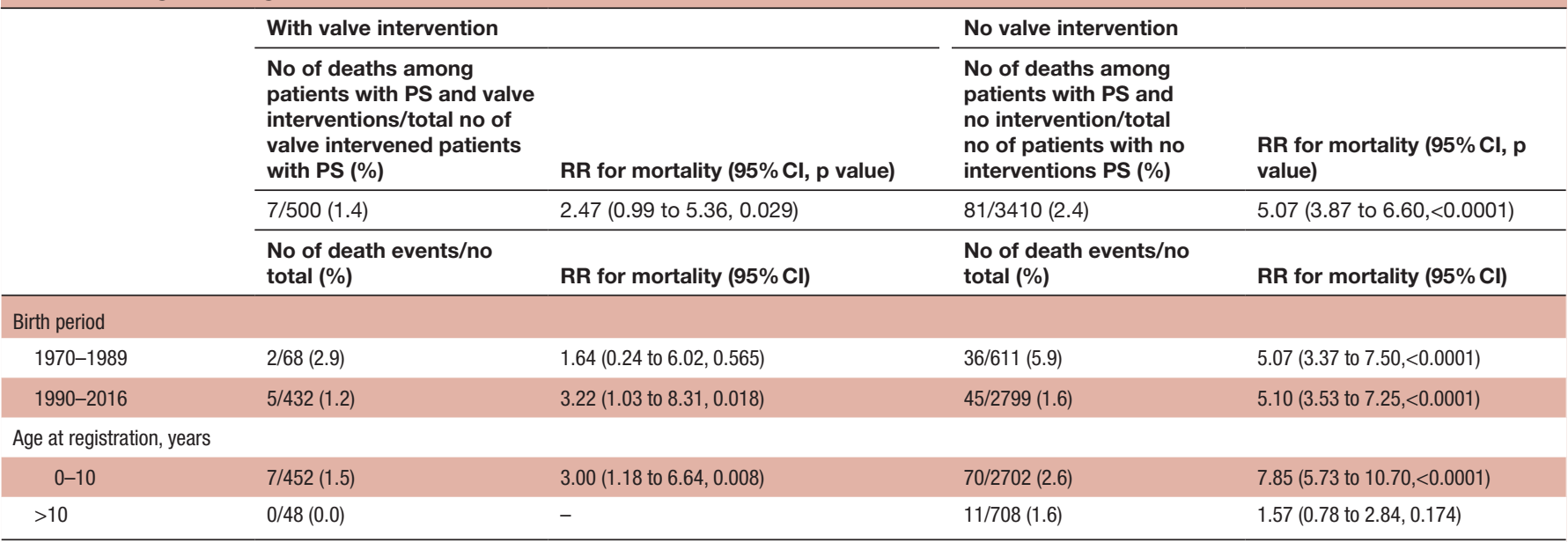

.PS, pulmonalis stenosis; RR, relative risk.;

\section{Statistical analysis}

Descriptive statistics were used to present demographic data. Data are presented as mean, median or IQR, as well as absolute numbers and percentages.

Mortality rates for cases versus controls, with valve interventions versus no valve interventions and men versus women, were estimated in different strata defined by birth period and age at first known registration of the disease and compared with rate ratios. The rate ratios are estimated according to the median-unbiased method (mid-p) and the corresponding confidence according to exact methods (mid-p), (R-package 'epitools', Epidemiology Tools, V.0.5-10.1, Tomas J. Aragon).

Kaplan-Meier plots with pointwise $95 \%$ CIs are presented illustrating group differences along with $\mathrm{p}$ values from log-rank tests. A two-tailed $p<0.05$ was considered significant. Matching of cases and controls was performed at birth and stratified by birth year and sex.

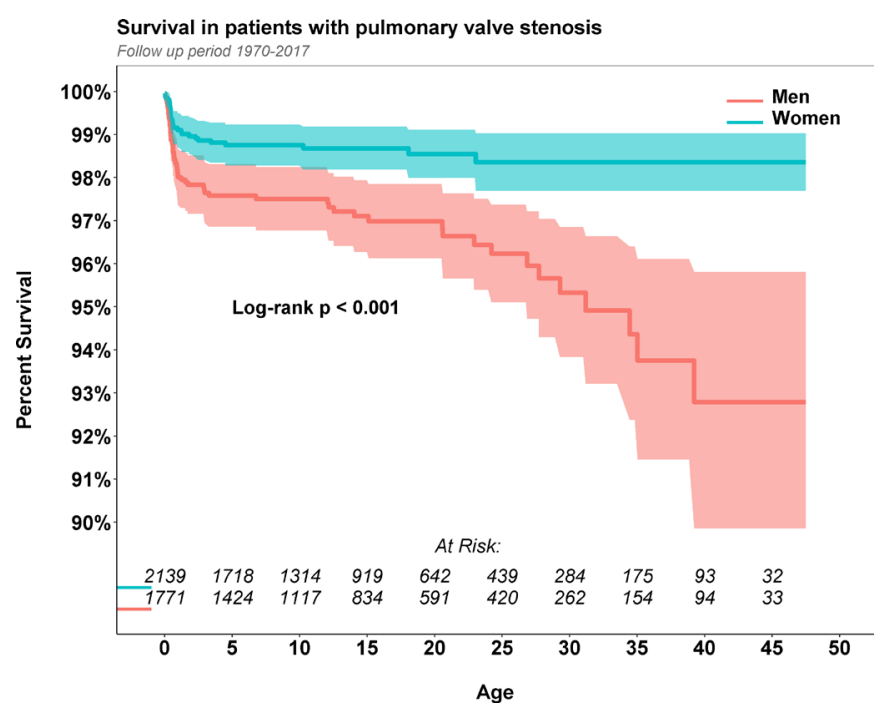

Figure 2 Kaplan-Meier estimated survival in patients with isolated pulmonary stenosis according to sex.
The data preparation was performed with logic programming system SWI-Prolog V.8.3 (www.swi-prolog. org). The statistical analyses were performed using $\mathrm{R}$ V.4.0 (R Foundation for Statistical Computing, Viena, Austria, www.r-project.org).

\section{Patient and public involvement}

There was no public or patient involvement in this study.

\section{RESULTS}

\section{Baseline characteristics}

Table 1 shows the characteristics of the study population. We included 3910 patients with PS and 38770 matched controls; $54.7 \%$ were female. The median age of PS diagnosis at registration was 0.7 years (IQR 0.3-7.0) and for patients with PS who underwent valve intervention was 0.5 years (IQR 0.3-3.7). A total of 2051 patients with PS $(52.5 \%)$ were diagnosed within the first year of life and 500 patients with PS $(12.7 \%)$ had at least one valve intervention (transcatheter or surgical).

\section{Mortality}

At the end of the study period, 88 patients with PS (2.3\%) and 192 controls $(0.5 \%)$ died. The median follow-up time from birth was 13.5 years (IQR 6.5-23.5). Overall Kaplan-Meier estimated survival in cases and controls is shown in figure 1 . The mortality was significantly higher in patients with PS than in controls $(\mathrm{p}=0.001)$, particularly during the first year after birth. The risk of mortality was 4.67 times higher (95\% CI 3.61 to $5.99, \mathrm{p}=0.001$ ) in patients with PS compared with controls. Thus, the risk of mortality by birth period and age at diagnosis is shown in table 2. All of the prespecified periods of birth showed a significant effect on the risk of mortality in patients with PS compared with controls. Patients with PS diagnosis within the first year after birth, had a markedly elevated risk of mortality, 10.99 (95\% CI 7.84 to $15.45, \mathrm{p}<0.001$ ). 


\begin{tabular}{|c|c|c|c|c|}
\hline & \multicolumn{2}{|l|}{ Men } & \multicolumn{2}{|l|}{ Women } \\
\hline & $\begin{array}{l}\text { Death events among men } \\
\text { with PS/total no of men with } \\
\text { PS, } n(\%)\end{array}$ & HR for mortality ( $95 \% \mathrm{Cl}, \mathrm{p}$ value) & $\begin{array}{l}\text { Death events among women } \\
\text { with PS/total no of women } \\
\text { with PS, } n(\%)\end{array}$ & $\begin{array}{l}\text { HR for mortality }(95 \% \mathrm{Cl}, \mathrm{p} \\
\text { value) }\end{array}$ \\
\hline & $59 / 1771(3.3)$ & 5.66 (4.09 to $7.74,<0.0001)$ & 29/2139 (1.4) & $3.48(2.24$ to $5.24,<0.0001)$ \\
\hline \multicolumn{5}{|l|}{ Birth period } \\
\hline 1970-1989 & 28/339 (8.3) & 6.06 (3.75 to $9.57,<0.0001)$ & $10 / 340(2.9)$ & 2.71 (1.27 to $5.25,0.004)$ \\
\hline 1990-2016 & $31 / 1432(2.2)$ & 5.37 (3.43 to $8.23,<0.0001)$ & $19 / 1799(1.1)$ & 4.13 (2.36 to $6.95,<0.0001)$ \\
\hline \multicolumn{5}{|c|}{ Age at registration, years } \\
\hline $0-10$ & 50/1427 (3.5) & 8.09 (5.57 to $11.68,<0.0001)$ & 27/1727 (1.6) & 5.36 (3.31 to $8.47,<0.0001$ ) \\
\hline$>10$ & $9 / 344(2.6)$ & $2.13(0.97$ to $4.17,0.039)$ & $2 / 412(0.5)$ & 0.65 (0.10 to $2.13,0.484)$ \\
\hline
\end{tabular}

PS, pulmonalis stenosis.;

No excess risk was observed in patients with a PS diagnosis at the age 1 to 10 years, or $>10$ years.

Only 7 out of the 88 deaths occurred among the 500 patients PS that underwent valve intervention; both valve intervention and non-valve intervention group of patients with PS displayed an increased risk of mortality compared with controls; however, with a borderline significance in the valve intervention group. Among patients with PS that did not undergo valve intervention, the risk of mortality was 5.07 (95\% CI 3.87 to 6.60) compared with controls. Higher mortality rates were observed in operated and unoperated patients with PS between 1990 and 2016 for patients with a PS diagnosis within the first decade of life (table 3).

In Kaplan-Meier survival analysis of women and men, there was significantly better survival in women than in men (figure 2). Both men and women appeared to have a higher risk of mortality compared with controls (RR 5.66, 95\% CI 4.09 to 7.74 and RR 3.48, 95\% CI 2.24 to 5.24 , both $\mathrm{p}<0.001$, respectively). Furthermore, men and women with a diagnosis of PS before 10 years old appeared to have a higher risk of mortality (table 4).

When analysing ICD codes for the leading cause of death among patients with PS, cardiac-related death was the most common cause. Cardiac-related death accounted for 42 of the 88 deaths $(48 \%)$ in patients with PS. Moreover, 35 (40\%) of the deaths were in PS patients with syndromes, cystic fibrosis or major malformations of inner organs or central nervous system. Mean age at death for men $(\mathrm{n}=59)$ were 7.1 years (median 0.8$)$ and for women $(\mathrm{n}=29) 2.6$ years (median 0.56$)$.

\section{DISCUSSION}

In this nationwide, register-based cohort study, we studied all patients with PS from birth to over the last half century in Sweden. To the best of our knowledge, this is the largest population-based study of patients with PS in this field.

The main finding of our study is that the mortality in patients with PS was almost five times higher than in matched controls without congenital heart disease, with over $90 \%$ deaths occurring in patients with PS who not have undergone any intervention. Furthermore, there was no change in risk of mortality over birth decades between men and women with PS. Diagnosis of PS within the first year of life appeared to be a specific high-risk group. However, when interpreting these data, there needs to be awareness that this study was designed to investigate patients with PS and no concomitant congenital heart lesions to avoid interference with analysis of mortality. This is in contrast to a recent study where more than $40 \%$ of the patients with repaired PS had concomitant lesions, which were predominantly atrial septal defects and persistent ductus arteriosus. ${ }^{10}$ Moreover, compared with other patient cohort studies, few $(12.8 \%)$ patients underwent any valve intervention.

Isolated PS, if mild to moderate, is generally thought to have a good prognosis, even if intervention is sometimes needed. ${ }^{14}$ No prior study has followed a nationwide cohort of patients since birth and, an increased risk of mortality in patients with PS on a population level has not been previously reported. This finding should have an effect on decisions regarding follow-up and on information regarding the importance of life-time follow-up in accordance with the latest European Society of Cardiology Guidelines, 2020. ${ }^{12}$ Our study suggests that the condition of isolated PS should not be generally considered a benign lesion. Analysis of subgroups, such as an operation, the time period and sex, indicated that an increased risk of mortality appeared almost regardless of subgroup. An exception to this would appear to be those with a registered diagnosis after 1 year of age but as the majority of those were born before the coverage of the patient registry was complete, an unknown proportion of infants and children with isolated PS may have died before being registered, contributing to the seemingly benign prognosis in this group. By contrast, patients with an early diagnosis within the first year of life, accounted for four out of five of deaths in this study and appeared to be a high-risk group. Extra attention should be paid to these patients in follow-up. Diagnosis of PS early in life could indicate severe disease.

However, in our study, the mortality rate in patients with valve interventions appeared to be low. This finding suggests that these patients do not represent a higher risk population for mortality (eg, from postoperative progressive pulmonary valve regurgitation and its related complications and reinterventions), but further analysis on this possibility is beyond 
the scope of this study. The higher mortality rate in patients with no valve interventions compared with patients with valve interventions in our study raises some concern. High prevalence of severe congenital comorbidity among deaths is noteworthy and could reflect a less active treatment approach to PS related to this comorbidity.

In our study, there was no increased risk of mortality in women with PS compared with controls. Previous studies have shown that patients with stenotic vitiae and pulmonary regurgitation have an increased risk of mortality in pregnancy. ${ }^{19}{ }^{20}$ This situation could increase risk in patients with unoperated PS and postsurgical pulmonary regurgitation. These studies suggested that an increased risk of PS in pregnancy had no effect on overall mortality in women.

\section{Limitations}

Patient-specific data reflecting the severity of PS were not available in this study, which meant that we were unable to classify the severity in patients with PS. Furthermore, the diagnosis of PS has not been validated. Under-reporting of surgery and interventions might have occurred because the patient registries were not uniformly complete from the beginning of the study period, and children dying from complications of PS between 1970 and 1986 but unrecognised in the death registry will not have been captured. Furthermore, general under-reporting of patients from the first part of the study period is possible for the same reason, with a proportion of children probably diagnosed early but not registered before being referred to specialist cardiology at a later stage.

This study has a national perspective and includes all types of clinics. Both tertiary centres with likely many severe cases as well as regional and local outpatient clinics, which may include many mild cases as well. Finally, even though we used data from an extended period from an entire nation, the absolute number of deaths in the PS group was low.

\section{CONCLUSION}

In this nationwide, register-based cohort study, we found that the risk of mortality in patients with PS was almost five times higher than controls. The risk of mortality in both patients with valve interventions and without valve interventions was higher than in matched controls. Patients with an early diagnosis of PS appear to have the highest risk of mortality. These findings suggest a close attention should be paid to long-term follow-up in this vulnerable group of patients.

Contributors KS has drafted the manuscript. All authors have made substantial contributions to the concept, design, analysis and interpretation of data. GL has performed statistical analysis. All authors have critically revised the manuscript. KS and ZM are responsible for the overall content.

Funding This work was funded by the Swedish state under the agreement between the Swedish government and the county councils (ALF agreement) (Grant Number: 236 611), the Swedish Heart-Lung Foundation (Grant Number: 20090724, 2018-0589), the Swedish Research Council framework grant (VRREG 2019-00193, 2018-02527) and Hjärtebarnsfonden (2/20 F0).

Competing interests None declared.

Patient consent for publication Not required.
Ethics approval The study was conducted in accordance with the ethical guidelines presented in the Declaration of Helsinki, revised in 2008. The study was approved by the regional board of ethics (Gbg 912-16, T 616-18).

Provenance and peer review Not commissioned; internally peer reviewed.

Data availability statement Data are available on reasonable request. All data relevant to the study are included in the article or uploaded as online supplemental information.

Open access This is an open access article distributed in accordance with the Creative Commons Attribution 4.0 Unported (CC BY 4.0) license, which permits others to copy, redistribute, remix, transform and build upon this work for any purpose, provided the original work is properly cited, a link to the licence is given, and indication of whether changes were made. See: https://creativecommons.org/ licenses/by/4.0/.

ORCID iD

Kristofer Skoglund http://orcid.org/0000-0002-9095-1218

\section{REFERENCES}

1 Moons P, Bovijn L, Budts W, et al. Temporal trends in survival to adulthood among patients born with congenital heart disease from 1970 to 1992 in Belgium. Circulation 2010;122:2264-72.

2 Mandalenakis Z, Rosengren A, Skoglund K, et al. Survivorship in children and young adults with congenital heart disease in Sweden. JAMA Intern Med 2017;177:224-30.

3 Mandalenakis Z, Giang KW, Eriksson P, et al. Survival in children with congenital heart disease: have we reached a peak at $97 \%$ ? $\mathrm{Am}$ Heart Assoc 2020;9:e017704.

4 Shuler CO, Black GB, Jerrell JM. Population-based treated prevalence of congenital heart disease in a pediatric cohort. Pediatr Cardiol 2013;34:606-11.

5 Hoffman JIE, Kaplan S. The incidence of congenital heart disease. $J$ Am Coll Cardiol 2002;39:1890-900.

6 Cuypers JAAE, Witsenburg M, van der Linde D, et al. Pulmonary stenosis: update on diagnosis and therapeutic options. Heart 2013;99:339-47.

7 Schmaltz AA, Bein G, Grävinghoff L, et al. Balloon valvuloplasty of pulmonary stenosis in infants and children--co-operative study of the German society of pediatric cardiology. Eur Heart J 1989;10:967-71.

8 Roos-Hesselink JW, Meijboom FJ, Spitaels SEC, et al. Long-term outcome after surgery for pulmonary stenosis (a longitudinal study of 22-33 years). Eur Heart J 2006;27:482-8.

9 Devanagondi R, Peck D, Sagi J, et al. Long-term outcomes of balloon valvuloplasty for isolated pulmonary valve stenosis. Pediatr Cardiol 2017;38:247-54.

10 Galian-Gay L, Gordon B, Marsal JR, et al. Determinants of long-term outcome of repaired pulmonary valve stenosis. Rev Esp Cardiol 2020;73:131-8.

11 Voet A, Rega F, de Bruaene AV, et al. Long-term outcome after treatment of isolated pulmonary valve stenosis. Int $\mathrm{J}$ Cardiol 2012;156:11-15

12 Giardini A, Cervi E. Asymptomatic adults with mild/moderate isolated native pulmonary valve stenosis are in need of treatment but not the kind you are thinking of! Heart 2014;100:1313-4.

13 Hayes CJ, Gersony WM, Driscoll DJ, et al. Second natural history study of congenital heart defects. results of treatment of patients with pulmonary valvar stenosis. Circulation 1993;87:I28-37.

14 Baumgartner H, De Backer J, Babu-Narayan SV, et al. 2020 ESC guidelines for the management of adult congenital heart disease. Eur Heart J 2021;42:563-645.

15 Gielen H, Daniëls O, van Lier H. Natural history of congenital pulmonary valvar stenosis: an echo and doppler cardiographic study. Cardiol Young 1999;9:129-35.

16 Guidelines for the management of congenital heart diseases in childhood and adolescence. Cardiol Young 2017;27:S1-105.

17 Mody MR. The natural history of uncomplicated valvular pulmonic stenosis. Am Heart J 1975;90:317-21.

18 Historiska åtgärdsklassifikationer. Available: https://www. socialstyrelsen.se/utveckla-verksamhet/e-halsa/klassificering-ochkoder/kva/historiska-klassifikationer/

19 Drenthen W, Boersma E, Balci A, et al. Predictors of pregnancy complications in women with congenital heart disease. Eur Heart $J$ 2010;31:2124-32.

20 Ducas RA, Javier DA, D'Souza R, et al. Pregnancy outcomes in women with significant valve disease: a systematic review and metaanalysis. Heart 2020;106:512-9. 